Federal Reserve Bank of Dallas

Globalization and Monetary Policy Institute

Working Paper No. 217

http://www.dallasfed.org/assets/documents/institute/wpapers/2014/0217.pdf

\title{
Trends and Cycles in Small Open Economies: Making the Case for a General Equilibrium Approach ${ }^{*}$
}

\author{
Kan Chen \\ International Monetary Fund \\ Mario Crucini \\ Vanderbilt University
}

November 2014

\begin{abstract}
Economic research into the causes of business cycles in small open economies is almost always undertaken using a partial equilibrium model. This approach is characterized by two key assumptions. The first is that the world interest rate is unaffected by economic developments in the small open economy, an exogeneity assumption. The second assumption is that this exogenous interest rate combined with domestic productivity is sufficient to describe equilibrium choices. We demonstrate the failure of the second assumption by contrasting general and partial equilibrium approaches to the study of a crosssection of small open economies. In doing so, we provide a method for modeling small open economies in general equilibrium that is no more technically demanding than the small open economy approach while preserving much of the value of the general equilibrium approach.
\end{abstract}

JEL codes: E32, F41

*Kan Chen, International Monetary Fund, $70019^{\text {th }}$ Street, NW, Washington, DC 20431. kan.chen2@imf.org. 202-623-7000. Mario J. Crucini, Department of Economics, Vanderbilt University, Box 1819, Station B., 415 Calhoun Hall, Nashville, TN 37235. 615-322-7357. mario.j.crucini@vanderbilt.edu. The views in this paper are those of the authors and do not necessarily reflect the views of the International Monetary Fund, the Federal Reserve Bank of Dallas or the Federal Reserve System. 


\title{
Trends and Cycles in Small Open Economies: Making The Case For A General Equilibrium Approach
}

\author{
Kan Chen \\ International Monetary Fund \\ kan.chen2@imf.org
}

\author{
Mario Crucini \\ Vanderbilt University \\ mario.crucini@vanderbilt.edu
}

September 30, 2014

\begin{abstract}
Economic research into the causes of business cycles in small open economies is almost always undertaken using a partial equilibrium model. This approach is characterized by two key assumptions. The first is that the world interest rate is unaffected by economic developments in the small open economy, an exogeneity assumption. The second assumption is that this exogenous interest rate combined with domestic productivity is sufficient to describe equilibrium choices. We demonstrate the failure of the second assumption by contrasting general and partial equilibrium approaches to the study of a cross-section of small open economies. In doing so, we provide a method for modeling small open economies in general equilibrium that is no more technically demanding than the small open economy approach while preserving much of the value of the general equilibrium approach.
\end{abstract}

\section{Introduction}

The veracity of business cycles differs dramatically across the nations of the world economy. Within our 68 country sample, the standard deviation of output growth ranges from an 
astounding $26.4 \%$ in Iraq to a mere $1.88 \%$ in the Netherlands; the median country is the Domincan Republic (3.83\%). The annual data used here is from the PWT and span the period 1971 to 2005 . Since our approach focuses on real as opposed to financial causes of business cycles, we omit the Great Recession from our analysis. Figure 1 presents a comprehensive view. Countries are organized into three groups in the figure and in subsequent analysis: 42 developing countries, 18 developed countries and the G-7 plus Australia (hereafter the G-8). While the grouping was not based on relative output variability, the developing countries are most the volatile and the G-8 the least volatile.

This paper builds upon Aguiar and Gopinath (2007) who argue that the greater veracity of business cycles in developing countries compared to more developed countries is due to a larger role for permanent shocks relative to (persistent) transitory shocks. Using simulations from a standard one-sector small open economy model, AG estimate that permanent shocks to productivity account for $96 \%$ of productivity growth in Mexico compared to only $37 \%$ in Canada. In their international cross-section, permanent shocks account for $84 \%$ of productivity growth variation for developing countries compared to $61 \%$ for developed countries. Notice that comparing the cross-country averages to the two case studies, Mexico is more representative of emerging markets than Canada is of developed economies in the sense that Canada has a stochastic trend component $24 \%$ lower than the average of developed economies. Following the logic of the permanent income hypothesis - a key facet of the equilibrium dynamics in the small open economy model - the larger the role of the trend shock the greater is the variance of consumption growth relative to that of income growth. Evidence consistent with this view is found in Figure 1 where the consumption growth volatility line is almost universally above the output volatility line in the upper panel (developing countries) whereas the opposite ranking of volatility is evident in the lower panel (the middle panel of countries fall in between these two groups).

Our point of departure from AG is the use of a general equilibrium model. The general equilibrium framework we use is the one-sector, two-country model of Baxter and Crucini (1995) with asset trade restricted to one-period non-contingent bonds. This particular model is chosen because it is the closest analytical framework to the small open economy model 
used by AG and thus ensures that the general equilibrium nature of the exercise isolates the differences between the two modeling approaches. The general equilibrium approach brings two insights to our understanding of business cycles that are absent in the partial equilibrium approach.

As first point out by Crucini (1991), a robust quantitative prediction of the general equilibrium model is that even with identical preferences, technology and stochastic processes for productivity shocks in both countries, the volatility of the business cycle is declining function of country size. The logic of this is straightforward. Consider a productivity shock in a very small nation. In such a case investment will increase to equate the domestic marginal product of capital with the fixed world interest rate. In contrast, the same shock in a large economy will require an increase in the real interest rate to equilibrate world savings and investment (i.e., the interest rate rises to clear the world bond market), crowding out some of the investment expansion. The output expansion is thus larger in the case of the smaller economy. This endogenous and asymmetric response would incorrectly be attributed to different stochastic processes across small and large economies using the partial equilibrium model and method of moments approach of AG. Avoiding this pitfall requires a general equilibrium approach. Crucini (1997) provides some quantitative analysis to suggest how large an economy must be to have a non-negligible impact on the world interest rate. Suffice to say, for purposes of comparing panel three with the upper two panels in Figure 1, this issue is important. In the application pursued by AG, they appropriately focus on differences among small open economies, namely, comparisons of nations in the first two panels, which mitigates this concern. At the same time, it is obviously useful to include large open economies to provide a more complete description of world business cycles. That is, to understand the underlying sources of fluctuations in world interest rates faced by small open economies.

The second implication of the general equilibrium approach is not innocuous even when the focus is on small open economies. The second point made by Crucini (1991) is that what matters for the response of a small open economy to a domestic productivity change is not just the size of its economy relative to the rest of the world, but whether or not pro- 
ductivity is also changing in the rest of the world at the same time. To see the logic of this, suppose that productivity diffuses within the period (i.e. is perfectly correlated across the large and small economies). With the same preferences and technology, all home and foreign economic variables will endogenously respond with the same equilibrium paths, output will be perfectly correlated across the countries, as will consumption, effort and investment. Essentially, each economy will respond as if it was closed because the intertemporal gains from trade are absent when productivity shocks are perfectly correlated across countries. The volatility of home and foreign output (and consumption) will be the same, not asymmetric as in Figure 1. The key insight here is that as we move from purely idiosyncratic to perfectly correlated productivity, a lot of interesting differences in volatility and comovement become possible. And, importantly, these properties can only be captured in general equilibrium because they require the researcher to match international business cycle correlation patterns. It requires that we understand the evolution of productivity differences across countries, not simply their univariate, within country, properties.

To capture this facet of productivity movements and the general equilibrium responses they evoke requires that we match the correlation of consumption and output growth across countries. Our approach to mapping a large cross-section of nations into a tractable general equilibrium framework is to rotate each of the 68 small open economies of our panel, in turn, through a two-country simulation in which that individual nation takes the role of the smaller trading partner coupled with the G-8, a country-size-weighted average of the G-7 plus Australia.

How does this moment matching of international business cycle comovement alter the model's implications for the nature of productivity disturbances? It distinguishes productivity disturbances (both permanent and transitory) by country of origin. Specifically, each nations productivity has its own idiosyncratic permanent and transitory components as in AG and, to this we add a country-specific factor loading to the permanent and transitory of the G-8 productivity process. One nation might share more of the stochastic trend with the G-8 and another might follow a more independent stochastic trend but be tied to the transitory component of the G-8. This stochastic model allows us to extend results of AG, 
who focus on the business cycle volatility puzzle (why are business cycles so volatile in developing nations), such that we may also consider the comovement puzzle (why are business cycles in developing nations so idiosyncratic).

The comovement puzzle, originally pointed out by Backus, Kehoe and Kydland (1992) is the fact that international consumption correlations are lower than income correlations. In the developed country sample, income growth correlations average 0.49 compared to 0.37 for consumption growth correlations (here the correlations are bilateral with the G- 8 aggregate as the reference country). This was the original motivation for $\mathrm{BC}$ to conceive the incomplete markets version of the standard one-sector, two-country stochastic growth model. The international comovement of the developing nation with the G-8 is much lower: output growth correlations average 0.16 and the consumption growth correlations average about zero, 0.038 .

Turning to specifics, our analysis begins with an attempt to replicate the basic finding of AG using a small open economy model very similar in structure to theirs in our broader sample of countries. And we do, at least qualitatively, finding that permanent productivity shocks dominate the variance of output growth of developing countries while playing a relatively small role in the case of developed countries. On average, permanent shocks account for almost three times as much of the output growth variability in developing countries compared to developed countries, $60 \%$ versus $22 \%$. Thus our results give the same basic message as theirs when the small open economy framework is utilized. The quantitative differences, however, are significant and arise for a number of reasons. First, we report decompositions of output variance while AG report decompositions of productivity variation, which are likely to be comparable due to the weak internal propagation mechanisms of the basic neoclassical the model, but certainly not identical. The data samples also differ in significant ways: i) we have a larger set of countries, 68 , compared to 26 in AG; ii) our time span is longer; and iii) our time periods are consistent across all countries whereas the AG samples differed by as much as a decade across some subsets of countries.

General equilibrium analysis, however, overturns the AG results. In the move from 
partial equilibrium analysis to general equilibrium analysis,the fraction of output variance explained by the permanent component of productivity rises from $22 \%$ to $60 \%$ for developed countries and drops from $60 \%$ to $52 \%$ for developing countries. The main reason for the change is that structural estimation using the general equilibrium model adds the correlation of macroeconomic aggregates between the G- 8 and each country to the set of moments used in the estimation of the productivity processes, which is infeasible when using the small open economy approach. The higher comovement of business cycles across the G8 and developed economies relative to the G- 8 and developing countries is what alters the composition of permanent and transitory shocks backed out of the general equilibrium model. The model and estimation attribute this international correlation structure to larger spillovers of the stochastic trend of productivity from the G- 8 to developed economies relative to developing economies. It remains true that permanent shocks are more important in developing countries in an absolute sense, but it is also true that transitory shocks are much larger in these economies as well. Business cycles do have more veracity in developing countries, but for the average country in these two groups, it seems that the fraction of output growth volatility accounted for the permanent shocks is comparable and actually slightly favors small open developed nations.

\section{The one-sector stochastic growth model}

Our use of the basic one-sector, two-country stochastic growth model is motivated by two objectives. The first is to stay as close as possible to the model specification utilized by AG. The second is to ensure that the general equilibrium and partial equilibrium versions of the model are structurally compatible. Three sources of novelty are introduced into these otherwise standard models. First, careful attention is given to international productivity spillovers from the large industrial block to each individual nation for both the permanent and transitory components of these shocks. Second, the cross-section of countries is comprehensive. Third, general equilibrium and partial equilibrium models are explicitly compared. The general equilibrium model is the one-sector, two country, DSGE model developed by 
Baxter and Crucini (1995). The partial equilibrium version of this model omits the world goods market clearing condition and adds a stochastic process to capture the evolution of the world interest rate. ${ }^{1}$ This section begins by quickly reviewing common features of these two versions of the one-sector model and concludes with a discussion of the differences.

\subsection{Preferences and technology}

Individuals in each country have Cobb-Douglas preferences over consumption and leisure

$$
U\left(C_{j t}, L_{j t}\right)=\beta^{t} \frac{1}{1-\sigma}\left[C_{j t}^{\theta} L_{j t}^{1-\theta}\right]^{1-\sigma}
$$

where parameter $\theta \in(0,1)$, and the inter-temporal elasticity of substitution is $1 / \sigma$.

The final good is produced using capital and labor. The production function is CobbDouglas and each country experiences stochastic fluctuations in the level of factor productivity, $A_{j t}$,

$$
Y_{j t}=A_{j t} K_{j t}^{1-\alpha} N_{j t}^{\alpha}
$$

The stochastic processes for productivity will involve both permanent and transitory components each potentially with a component common across nations and unique to the nation. The processes are described in more detail and estimated in the next section.

The capital stock in each country, depreciates at the rate $\delta$ and is costly to adjust:

$$
K_{j t+1}=(1-\delta) K_{j t}+\phi\left(I_{j t} / K_{j t}\right) K_{j t},
$$

where $\phi(\cdot)$ is the adjustment cost function. As in Baxter and Crucini (1995), adjustment costs have the following properties: i) at the steady-state, $\phi(I / K)=I / K$ and $\phi^{\prime}(I / K)=$ 1 so that in the deterministic solution to the model the steady state with and without adjustment costs are the same and ii) $\phi^{\prime}>0, \phi^{\prime \prime}<0$.

\footnotetext{
${ }^{1} \mathrm{AG}$ incorporate a domestic interest rate response to home debt relative to productivity, but this plays a minor quantitative role in their exercise.
} 


\subsection{Closing the model}

Following Baxter and Crucini (1995), the two country general equilibrium model is closed by imposing one intertemporal budget constraint and world goods market clearing. The intertemporal budget constraint is:

$$
P_{t}^{B} B_{j t+1}-B_{j t}=Y_{j t}-C_{j t}-I_{j t}
$$

where $B_{j t+1}$ denotes the quantity of bonds purchased in period $t$ by country $j . \quad P_{t}^{B}$ is the price of a bond purchased in period $t$ and maturing in period $t+1$. The bond is not state-contingent, it pays one physical unit of output in all states of the world. Implicitly this defines, $r_{t}$, the real rate of return for the bond (i.e., $\left.P_{t}^{B} \equiv\left(1+r_{t}\right)^{-1}<1\right)$. The price of this bond is endogenous in the two-country equilibrium model, determined by the market-clearing condition in the world bond market.

The world goods market clearing condition is:

$$
\pi_{0}\left(Y_{0 t}-C_{0 t}-I_{0 t}\right)+\pi_{j}\left(Y_{j t}-C_{j t}-I_{j t}\right)=0
$$

where $\pi_{j}$ denotes the fraction of world GDP produced by country $j$. These weights are necessary to define market clearing because the quantities in the constraint are in domestic per capita terms.

The small open economy is closed with an inter-temporal budget constraint identical to (4). However, the discount rate follows an exogenous stochastic process describe below. In addition, the following boundary condition is imposed:

$$
\lim _{t \rightarrow \infty} \beta^{t} p_{j t} B_{j t+1}=0
$$

where $p_{j t}$ is the multiplier on the inter-temporal budget constraint of small open economy $j$.

Parameterization of tastes and technology are set to values commonly used in the liter- 
ature. The value of $\beta$ is set to be 0.954 , so that the annual real interest rate is $6.5 \%$. The parameter of relative risk aversion $\sigma$ is 2 and labor's share $\alpha$ in the production function is 0.58. In the Cobb-Douglas preference function, $\theta=0.233$. The depreciation rate of capital, $\delta$, is assigned a value of 0.10 . The elasticity of the investment-capital ratio with respect to Tobin's Q is $\eta=-\left(\phi^{\prime} / \phi^{\prime \prime}\right) \div(i / k)=15$.

\subsection{Exogenous shocks}

Moving from theory to quantitative implications involves estimation of the stochastic process for productivity in each country. Partial equilibrium models require specification of stochastic processes for home country productivity and the domestic interest rate. General equilibrium models require the estimation of stochastic processes for both home and foreign productivity since the interest rate is endogenous, determined by market clearing in the bond market. Our specification and estimation method for each of these stochastic processes is discussed in turn below.

\subsubsection{Total factor productivity}

Beginning with the G-8 as an aggregate economic entity, indexed by 0 , the logarithm of productivity is the sum of a non-stationary and a stationary component, $\ln A_{0 t}=\ln A_{0 t}^{P}+\ln A_{0 t}^{T}$. The non-stationary component follows a pure random walk,

$$
\ln A_{0 t}^{P}=\ln A_{0 t-1}^{P}+\ln \varepsilon_{0 t}^{P},
$$

and the stationary component follows an $\mathrm{AR}(1)$ process:

$$
\ln A_{0 t}^{T}=\rho_{0} \ln A_{0 t-1}^{T}+\ln \varepsilon_{0 t}^{T} .
$$

The innovations are drawn from independent normal distributions with different standard deviations: $\varepsilon_{0 t}^{T} \sim N\left(0, \sigma_{0}^{T}\right), \varepsilon_{0 t}^{P} \sim N\left(0, \sigma_{0}^{P}\right)$. 
As the G- 8 is by far the largest region and we assume that productivity spills over from G-8 to the G-60 and not the reverse, simulations of the closed economy version of the benchmark model are used to estimate the parameters of the productivity components of the G-8 (effectively this involves setting $\pi=1$ in the general equilibrium model described earlier). Inputs into the estimation are G-8 aggregates, constructed as country-size-weighted averages of output growth, consumption growth and the logarithm of the consumptionoutput ratio. Productivity parameters are chosen to match the observed sample variances of these three key macroeconomic variables.

The outcome of the moment-matching exercise is reported in Table 1. The average difference (across countries) between the moments from the data and from the model simulation, reported in the upper panel of the table, is less than $10 \%$ in all cases. The estimated persistence of the stationary component of productivity is 0.85 , which, when converted to a quarterly estimate matches closely the existing closed economy real business cycle literature that focuses exclusively on persistent, but transitory shocks and output fluctuations at business cycle frequencies. It is interesting that the innovations to the two components have near identical standard deviations, 1.2 and 1.1. When combined with the estimated persistence of the stationary component, the implication is that the unconditional variance of the transitory shock adds about $18 \%$ more to the variance of productivity growth than the permanent shock. These estimates accord with Crucini and Shintani (2014) who estimate a bivariate error-correction model of output and consumption growth for each of the G-7 nations and Australia and find comparable contributions of stochastic trend and cycle shocks.

The stochastic process for total factor productivity of the small open economies (nations outside of the G-8 block) is specified in two different ways. Following the existing literature and our specification of G-8 productivity, productivity in country $j$ is the sum of these two stochastic components,

$$
\ln A_{j t}=\ln A_{j t}^{P}+\ln A_{j t}^{T} .
$$


The permanent component of TFP in country $j$ is,

$$
\ln A_{j t}^{P}=\ln A_{j t-1}^{P}+\ln \varepsilon_{j t}^{P},
$$

and the stationary component is an $\mathrm{AR}(1)$ process :

$$
\ln A_{j t}^{T}=\rho_{j} \ln A_{j t-1}^{T}+\ln \varepsilon_{j t}^{T} .
$$

As was the case of innovations to the components of TFP of the G- $8, \varepsilon_{j t}^{P}, \varepsilon_{j t}^{T}$, are i.i.d. draws from normal distributions both with mean zero, but different standard deviations. For expositional convenience, the distributions are expressed as: $\varepsilon_{j t}^{T} \sim N\left(0, v_{j}^{T} \sigma_{0}^{T}\right), \varepsilon_{j t}^{P} \sim$ $N\left(0, v_{j}^{P} \sigma_{0}^{P}\right)$. Thus, $v_{j}^{P}$ and $v_{j}^{T}$, are the standard deviations of the innovations to the permanent and temporary components of productivity in country $j$ relative to their counterparts in the G-8, estimated earlier. For purposes of parsimony and tractability, the persistence of the transitory component of TFP in all countries is set equal to its G-8 counterpart: $\rho_{j}=\widehat{\rho}_{0}=0.85 \forall j .^{2}$

The second specification of total factor productivity is the correctly specified one in the sense that it is estimated by simulating the two country general equilibrium model. Specifically, with the G-8 productivity processes estimated from the closed economy general equilibrium model, the stochastic process for TFP in the small open economy in the twocountry general equilibrium model is specified as: $\ln A_{j t}=\ln A_{j t}^{P}+\ln A_{j t}^{T}+\omega_{j}^{P} \ln A_{0 t}^{P}+$ $\omega_{j}^{T} \ln A_{0 t}^{T}$.The parameters $\omega_{j}^{P}$ and $\omega_{j}^{T}$ are factor loadings capturing non-stationary and stationary productivity spillovers from the G- 8 to country $j$. These spillovers are necessary to match international business cycle comovement patterns across the G-8 and individual small open economies in our panel data.

Thus, the correct structural model is taken to be the two-country general equilibrium

\footnotetext{
${ }^{2}$ While this choice of persistence for the stationary component is based on maintaining some aspects of tractability and symmetry across countries, it turns out this is equivalent to a quarterly persistence of 0.96 and thus consistent with the findings of Aguiar and Gopinath (2007). They estimated persistence of their transitory component of productivity at the quarterly frequency of 0.97 for Canada and 0.95 for Mexico, respectively. Moreover, they find this value is close to what the persistence of transitory component of productivity equals for a number of other developed countries.
} 
model with a block-recursive bivariate model for TFP of country $j$ and the G-8 $(j=0)$ :

$$
\left[\begin{array}{l}
\ln A_{j t} \\
\ln A_{0 t}
\end{array}\right]=\left[\begin{array}{cccc}
1 & 1 & \omega_{j}^{P} & \omega_{j}^{T} \\
0 & 0 & 1 & 1
\end{array}\right]\left[\begin{array}{c}
\ln A_{j t}^{P} \\
\ln A_{j t}^{T} \\
\ln A_{0 t}^{P} \\
\ln A_{0 t}^{T}
\end{array}\right]
$$

As a matter of accounting, the true productivity process of the small open economy is the sum of four terms, the first two terms are permanent and temporary components coming from domestic productivity and the second two terms are permanent and temporary productivity spillovers from the G-8.

Naturally, the response of an open economy to a permanent or temporary productivity shock will depend on whether the shock is of home or foreign origin. As we shall see, the spillovers are necessary to match the international correlation of business cycles, which are absent from the set of moments available using the partial equilibrium approach. This is what distinguishes general equilibrium analysis from partial equilibrium analysis of international business cycles.

To estimate the nation-specific factor loadings on G-8 productivity components, $\omega_{j}^{P}$ and $\omega_{j}^{T}$, and the relative standard deviations of nation-specific productivity innovations, $v_{j}^{T}$ and $v_{j}^{P}$, the general equilibrium open economy model is used. Specifically, in each simulation, the G- 8 takes the role of the large open economy and nation $j$ takes the role of the small open economy in the model. The relative size of the small country is set to the fraction of world GDP that country produces, on average, over the sample period of observation. The model is simulated for a range of values for the relative innovation variance of the permanent and transitory shock to the small country (keeping the G-8 processes as previously estimated) to match: i) the variance of GDP growth of country $j$; ii) the variance of consumption growth of country $j$; iii) the correlation of GDP growth between the G-8 and country $j$ and iv) the correlation of consumption growth between the G-8 and country $j$.

The heterogeneity of business cycles across developing and developed countries is stark. 
The standard deviation of output growth is twice as high in developing countries compared to developed countries, 5.98 versus 3.01. Thus, it is not surprising that the standard deviation of productivity innovations are estimated to be much higher in developing countries. Less obvious and more interesting is a comparison of the two components that determine national productivity: the innovations to the permanent component has a standard deviation almost twice that of the transitory component in the case of developing countries, 4.21 versus 2.14 . In contrast, the innovations to the two components are indistinguishable for the developed countries (1.18 and 1.19) and recall, they were also very similar the G-8 as a block (see Table 1). The prominence of the permanent shocks in developing countries is the key insight from AG. Intuitively, as shocks become more persistent the wealth effect on consumption rises causing income and consumption to move more closely over the business cycle. This helps the model account for the fact that the standard deviation of consumption growth is higher than that of output growth for developing countries while the reverse is true for developed countries.

The international business cycle literature has emphasized the importance of matching the international comovement of business cycles. The challenge in doing so using models featuring complete risk-sharing led Backus, Kehoe and Kydland (1992) to coin the phrase 'international comovement puzzle.' That is, with complete financial markets, the consumption correlation is predicted to be near unity, bounding the output correlation from above. They pointed this out in the context of developed nations, where consumption growth correlations with the G- 8 block, average 0.37 , compared to 0.49 for output correlations. The puzzle worsens when the sample is extended; the correlation of G-8 consumption growth with that of a typical developing country is about zero and the output growth correlation averages 0.16 .

This is where the general equilibrium version of the prototype small open economy model, developed by Baxter and Crucini (1995), is particularly useful. Essentially, what matters for consumption comovement is the international correlation of wealth. Since permanent shocks have larger wealth effects than transitory ones, what is needed to account for idiosyncratic consumption variability are persistent nation-specific productivity shocks. As Table 2 clearly 
indicates, the spillover of the permanent G- 8 productivity innovation for developing countries is only about $1 / 3$ as large as its counterpart for developed countries, 0.7 versus 2.5 . As one might have anticipated, the stochastic trend component of productivity is more similar when comparing developed countries to the G-8 than when comparing developing countries to the G-8. This combined with the relatively large innovation to the idiosyncratic permanent component of productivity in the typical developing country helps to account for both their high relative volatility and low correlation of consumption with the G-8.

\subsubsection{Interest rate shocks}

In SOE models, domestic productivity shocks play a central role as they should, just as in the general equilibrium models. However, foreign productivity shocks are not explicitly modeled and thus the model is mis-specified. To explore implications of this we assume as Mendoza (1991) did that the discount rate follows an AR(1) process:

$$
\ln P_{t}^{B}=\gamma_{j} \ln P_{t}^{B}+\ln \varepsilon_{j t}^{B},
$$

where $0<\gamma_{j}<1$ denotes the persistence of the logarithm of the bond price, and $\varepsilon_{j t}^{B}$ is an iid draw from a normal distribution with zero mean and standard deviation $\sigma_{j}^{P B}{ }^{3}$

To parametrize the real interest rate we match the same second moments as before (namely, the variance of output and consumption growth), but use the partial equilibrium model of a small open economy as the simulation model. Table 3 shows the estimation results for the median country and two points in the cross-sectional distribution of the 60 small countries. Under the first model with transmission of TFP shock from G-8 (columns labelled with Yes for presence of spillovers), we observe three patterns in the table. First, the persistence of the bond price process is similar in both developing and developed countries. The median autocorrelation coefficient is 0.25 for developing countries and 0.23 for developed

\footnotetext{
${ }^{3}$ Recent extensions of this basic approach allow for a differential to arise between the domestic interest rate and the world interest rate and for that differential to be a function of domestic productivity, as Uribe and Yue (2006). The latter formulation is intended to allow for the possibility that changes in domestic productivity change the probability of default and this feeds back into banks willingness to lend. While this is an important extension of the basic framework, this formulation still abstracts from the differential response of a country to a home and global productivity change.
} 
countries. Second, the median standard deviation of the innovation term is the same for developing and developed countries as well. This is reassuring since it would be odd for the estimated processes to differ given our approach presumes a single world real interest rate and full integration of international bond markets at that common rate. It is worth noting that the developing country group is more asymmetric than the developed country group as evident in the much higher persistence and innovation standard deviation of the implied real interest rate in the tail of the cross-country distribution.

The calibration results of bond price process changes significantly when the small open economy model is assumed to be driven by only domestic productivity shocks. First, the median value of standard deviation for the innovation term increases from 0.1 percent to 0.4 percent for both developed and developing countries. The reason is straightforward: as foreign TFP shocks are absent when spillovers are omitted from the shock vector, this is compensated by a larger role assigned to the interest rate process. This result shows that underestimation of the magnitude of TFP shocks, especially the spillovers from abroad, may lead one to overestimate the role of the interest rate shock. Second, the partial equilibrium model results in an estimate of the interest rate shock in developing countries much less persistent than in developed countries. The median value of $\widehat{\gamma}_{j}$ is 0.10 for developing countries, and 0.55 for developed ones. Recall that in our GE model, the estimated factor loading on the permanent TFP shock in the G-8 is much larger in the case of developed economies. The absence of this shock in the SOE model raises the persistence of the interest rate shock since it serves as a proxy for the productivity shocks transmitted from the G-8.

\section{Variance Decomposition}

With the calibration of the DGSE and SOE models complete, we are in a position to compute variance decompositions of output growth into the underlying exogenous sources of variation under the null and alternative models. Recall, the null model is the two-country general equilibrium model with international productivity spillovers.

Table 4 reports the results using the small open economy model without spillovers as 
this corresponds most closely to the analysis of AG. Beginning with the pooled results for all countries the permanent and transitory shocks account for almost the same fraction of output growth fluctuations, $48.6 \%$ and $44 \%$, respectively with the world interest rate accounting for the remainder. However, these averages obscure considerable heterogeneity in the crosssection. Dividing the sample into developing and developed countries the asymmetry point out by AG shows up vividly. In fact, the roles of the permanent and transitory shocks are almost transposed across the two groups with the permanent shock accounting for about $59.9 \%$ of the variance in developing countries while the transitory shock accounts for about the same fraction $(63.9 \%)$ in the case of developed economies. The interest rate plays a relative minor role in both cases, but is more important for the developed economies than the developing economies.

The conclusion of AG about the dominance of permanent shocks in developing countries appears to be much stronger in our broader sample than the AG sample. Note that our time periods overlap across countries while those of AG did not. This might be expected in the sense that the AG sample of developing countries tends to start after the global recession of the 1980's while that of developing countries tends to include the period, making the two groups appear more similar in volatility than they truly are over comparable historical periods.

Turning to Table 5, the result when the simulation model is correctly specified as a two country general equilibrium model with productivity spillovers, the asymmetry in the contribution of permanent and transitory shocks across the country groups is now the reverse of what AG found. That is, the permanent shocks now play a relatively important role in the case of the developed countries, $60 \%$ versus $51.6 \%$ for developing countries. Notably this tendency is preserved in the narrower sample used by AG (not shown).

The right-most panel shows that the partial equilibrium model may be calibrated and simulated to mimic these properties of the data. Unfortunately this might be described as false comfort for partial equilibrium modelers because the correctly specified productivity process can only be recovered from the general equilibrium simulations. Recall why this 
must be so: it is necessary to add international comovement of macroeconomic aggregates to recover the correct international productivity spillovers and those are simply not available in the partial equilibrium model setting.

The lower panel of Table 5 breaks the permanent and transitory components into the contributions of home productivity and G8 spillovers. The differences between general equilibrium and partial equilibrium modeling is now evident. In particular, the small open economy model does not reproduce the correct decomposition of the permanent and temporary components into home and foreign (spillovers). For example, in the case of developed countries, the correct decomposition of the permanent shocks is to assign $45.5 \%$ of the variation to a spillover from the G- 8 . The small open economy model assigns only $13.2 \%$ to this spillover. The reason the prediction is so far off is that the small open economy predicts that agents will respond in the same fashion to shocks of domestic or foreign origin provided they have the same stochastic properties (i.e. permanent or transitory) whereas this is obviously not the case in a general equilibrium context where the source of the shock is of paramount importance in determining the quantitative response and often the sign of the response.

The averages are also less stark than the country-by-country results since the specification errors tend to average out to some extent. Figure 2 provides a more complete view of the differences between the general equilibrium and partial equilibrium models. The figure depicts the fraction of output growth variance attributable to the permanent shocks (home and G-8 spillover) predicted by these two modeling approaches. Since the interest rate is endogenous in the general equilibrium model, the fraction of variance attributed to productivity is an upper envelope of that predicted by the small open economy. Interestingly, for most countries the specification errors are trivial, but for a significant minority the errors are enormous. The reader is reminded that in this exercise the spillovers estimated using the general equilibrium model are included in the partial equilibrium simulations in this comparison. Since the spillovers are not identified in the partial equilibrium model these comparisons should be viewed as lower bounds on the errors. That is, only if the productivity processes could be directly observed would this small open economy specification be feasible to simulate and compare to the small open economy results in Figure 2. 
Figure 3 presents a more pragmatic comparison. It contrasts the small open economy approach under the correct specification with productivity spillovers from G-8 and the more common practice (as in AG) where the small open economy model is simulated with only domestic permanent and transitory shocks. Note that the small open economy approach gets the correct variance decomposition on average (across countries) even when spillovers are ignored. However, the errors of variance accounting country-by-country are very substantial and not randomly distributed in the cross-section. The role of permanent shocks is underestimated when spillovers are ignored for developed economies, but overestimated when spillovers are ignored in the case of developing countries.

\section{Concluding remarks}

In this paper we have compared the performance of a standard SOE model with an analytically comparable two-country DSGE model. We conducted variance decompositions for 60 small economies using both modeling frameworks. We find that the main limitation of the SOE model is that it cannot capture the role of permanent TFP spillovers from the G- 8 . This result is robust in the entire cross-section of nations, but is more quantitatively important for small developed countries, who share more of a stochastic trend in productivity with the G-8. It is simply not true that the small open economy framework is justifiable on the grounds that small economies do not affect the world interest rate. The practical difficulty with the small open economy approach is that is greatly limits the ability of researchers to capture the different national responses of internationally integrated economies to common and idiosyncratic shocks, be they permanent or transitory in nature. Our paper has provided a methodology that allows researchers to study economic interactions of a large number of heterogeneous and small open economies in general equilibrium without exploding the dimensionality of the state space. Essentially it boils down to modeling a large aggregate economic region in general equilibrium with a small open economy. One limitation of the approach developed here is that it abstracts from the possibility that shocks outside of the G-8 are large enough to alter the world interest rate. With the emergence of the BRICs, for 
example, it is important to extend the approach to allow for more than one block of nations to alter the equilibrium dynamics of the many smaller economies of the world. We leave this extension to future work. 


\section{References}

Aguiar, M. And G. Gopinath, "Emerging Market Business Cycles: The Cycle is the Trend," Working Paper 10734, National Bureau of Economic Research, September 2004.

— , "Emerging Market Business Cycles: The Cycle is the Trend," Journal of Political Economy 115 (2007), 69-102.

Backus, D. K., P. J. Kehoe and F. E. Kydland, "International Real Business Cycles," The Journal of Political Economy 100 (1992), 745-775.

Baxter, M. And M. J. Crucini, "Explaining Saving-Investment Correlations," American Economic Review 83 (June 1993), 416-36.

__ "Business Cycles and the Asset Structure of Foreign Trade," International economic review 36 (1995), 821-854.

Burstein, A., C. Kurz and L. Tesar, "Trade, production sharing, and the international transmission of business cycles," Journal of Monetary Economics 55 (2008), 775 - 795.

Calvo, G. A. and E. G. Mendoza, "Capital-Markets Crises and Economic Collapse in Emerging Markets: An Informational-Frictions Approach," American Economic Review 90 (May 2000), 59-64.

Chari, V., P. Kehoe and E. R. McGrattan, "Sudden Stops and Output Drops," Working Paper 11133, National Bureau of Economic Research, February 2005.

Crucini, M., The Transmission of Business Cycles in the Open Economy, Ph.D. thesis, University of Rochester (1991).

Crucini, M. J., "Country Size and Economic Fluctuations," Review of International Economics 5 (1997), 204-220.

Crucini, M. J., A. Kose And C. Otrok, "What are the driving forces of international business cycles?," Review of Economic Dynamics 14 (2011), 156-175. 
Crucini, M. J. And M. Shintani, "Measuring business cycles by saving for a rainy day," Canadian Journal of Economics (2014).

De Walque, G., F. Smets and R. Wouters, "An Estimated Two-Country DSGE Model for the Euro Area and the US Economy," Technical Report, European Central Bank, 2005.

Devereux, M. B. And A. Sutherland, "A portfolio model of capital flows to emerging markets," Journal of Development Economics 89 (2009), 181 - 193.

Garcia-Cicco, J., R. Pancrazi and M. Uribe, "Real Business Cycles in Emerging Countries?," American Economic Review 100 (2010), 2510-31.

Heathcote, J. and F. Perri, "Financial autarky and international business cycles," Journal of Monetary Economics 49 (2002), 601 - 627.

Mendoza, E. G., "Real Business Cycles in a Small Open Economy," American Economic Review 81 (September 1991), 797-818.

— (2010), 1941-66.

Neumeyer, P. A. And F. Perri, "Business cycles in emerging economies: the role of interest rates," Journal of Monetary Economics 52 (2005), 345 - 380.

Obstfeld, M. And K. Rogoff, "The Six Major Puzzles in International Macroeconomics: Is There a Common Cause?," Working Paper 7777, National Bureau of Economic Research, July 2000.

QuAH, D., "The Relative Importance of Permanent and Transitory Components: Identification and Some Theoretical Bounds," Econometrica 60 (1992), 107-118.

Schmitt-Grohe, S. And M. URIBe, "Closing small open economy models," Journal of International Economics 61 (2003), 163 - 185.

URIBE, M. AND V. Z. Yue, "Country spreads and emerging countries: Who drives whom?," Journal of International Economics 69 (2006), 6 - 36. 
Table 1 - Estimates of G-8 Productivity Processes

\begin{tabular}{lcc}
\hline \hline & Data & Model \\
\hline Standard deviation of: & & \\
GDP growth & 1.80 & 1.94 \\
Consumption growth & 1.28 & 1.15 \\
Consumption-GDP ratio & 1.44 & 1.32 \\
& & \\
G-8 productivity parameters & & \\
Std. dev. of permanent innovation & & 1.1 \\
Persistence & 0.85 & \\
Std. dev. of transitory innovation & & \\
\hline
\end{tabular}

Notes: The upper panel reports the moments of G-8 data in the first column that are matched with the model simulations reported in the second column. The closed economy version of the model is simulated 2,700 times with the range of parameters as follows: $\widehat{\rho}_{0} \in[0.40,0.95], \widehat{\sigma}_{0}^{T} \in[0.006,0.02]$ and $\widehat{\sigma}_{0}^{p} \in[0.006,0.02]$. The parameters that best fit the model to the data are reported in the lower panel. 
Table 2 - Estimates of G-60 Productivity Processes

\begin{tabular}{lccccc}
\hline \hline & \multicolumn{2}{c}{ Developing } & & \multicolumn{2}{c}{ Developed } \\
\cline { 2 - 3 } \cline { 5 - 6 } & Data & Model & & Data & Model \\
Std. Dev. of consumption & 7.77 & 7.74 & & 2.45 & 4.43 \\
Std. Dev. of GDP & 5.98 & 7.16 & & 3.01 & 4.32 \\
& & & & \\
Corr. with G-8 GDP & 0.16 & 0.17 & & 0.49 & 0.48 \\
Corr. with G-8 consumption & 0.038 & 0.042 & & 0.37 & 0.38 \\
& & & & \\
Innovation standard deviations & & & & \\
relative to G-8 counterparts & & & & \\
$v_{j}^{P} \in[0.1,15]$ & & & & \\
$v_{j}^{T} \in[0.1,15]$ & & & & \\
Factor loadings on G-8 spillovers & & & & \\
$\omega_{j}^{P} \in[-15,15]$ & & & & & \\
$\omega_{j}^{T} \in[-15,15]$ & & & & & \\
\hline
\end{tabular}


Table 3 - Bond Price Shock Parameters

\begin{tabular}{|c|c|c|c|c|}
\hline \multirow[b]{2}{*}{ Spillovers } & \multicolumn{2}{|c|}{ Developing } & \multicolumn{2}{|c|}{ Developed } \\
\hline & Yes & No & Yes & No \\
\hline Persistence & $\begin{array}{c}0.25 \\
(0.23,0.60)\end{array}$ & $\begin{array}{c}0.10 \\
(0.00,0.55)\end{array}$ & $\begin{array}{c}0.23 \\
(0.20,0.24)\end{array}$ & $\begin{array}{c}0.55 \\
(0.15,0.79)\end{array}$ \\
\hline Innovation variance & $\begin{array}{c}0.001 \\
(0.001,0.008) \\
\end{array}$ & $\begin{array}{c}0.004 \\
(0.002,0.006) \\
\end{array}$ & $\begin{array}{c}0.001 \\
(0.001,0.003) \\
\end{array}$ & $\begin{array}{c}0.004 \\
(0.003,0.005)\end{array}$ \\
\hline
\end{tabular}


TABLE 4. OUTPUT VARIANCE DECOMPOSITIONS, SMALL OPEN ECONOMY MODEL

\begin{tabular}{|c|c|c|c|c|c|c|}
\hline \multirow{3}{*}{$\begin{array}{l}\text { Source of shock } \\
\text { Type of shock }\end{array}$} & \multicolumn{3}{|c|}{ Variance Decomposition } & \multirow{3}{*}{ Total } & \multirow{3}{*}{$\begin{array}{c}\text { Number } \\
\text { of } \\
\text { Countries }\end{array}$} & \multirow{3}{*}{$\begin{array}{c}\text { Std. dev. } \\
\text { of } \\
\text { Output }\end{array}$} \\
\hline & Home & Home & World & & & \\
\hline & Permanent & Transitory & Interest rate & & & \\
\hline All Countries & 48.6 & 44.0 & 7.5 & 100 & 60 & 5.2 \\
\hline Developing & 59.9 & 35.4 & 4.7 & 100 & 42 & 6.0 \\
\hline Developed & 22.2 & 63.9 & 13.8 & 100 & 18 & 3.2 \\
\hline AG Sample & 34.6 & 54.0 & 11.4 & 100 & 20 & 3.3 \\
\hline Developing & 49.9 & 47.2 & 2.8 & 100 & 9 & 4.2 \\
\hline Developed & 22.1 & 59.5 & 18.4 & 100 & 11 & 2.5 \\
\hline
\end{tabular}

Notes:Productivity spillovers are abstracted from in this specification because they would not be identified using the small open economy model. 
TABLE 5. OUTPUT VARIANCE DECOMPOSITIONS, MODELCOMPARISONS

\begin{tabular}{|c|c|c|c|c|c|c|c|c|c|}
\hline Model & \multicolumn{4}{|c|}{ DSGE } & \multicolumn{5}{|c|}{$\mathrm{SOE}$} \\
\hline Source of shock & \multicolumn{2}{|c|}{ Home + G8 } & \multicolumn{2}{|c|}{ Home + G8 } & \multicolumn{2}{|c|}{ Home + G8 } & \multicolumn{2}{|c|}{ Home + G8 } & Interest \\
\hline Type of shock & \multicolumn{2}{|c|}{ Permanent } & \multicolumn{2}{|c|}{ Transitory } & \multicolumn{2}{|c|}{ Permanent } & \multicolumn{2}{|c|}{ Transitory } & rate \\
\hline All Countries & \multicolumn{2}{|c|}{54.1} & \multicolumn{2}{|c|}{45.9} & \multicolumn{2}{|c|}{45.7} & \multicolumn{2}{|c|}{43.3} & 11.0 \\
\hline Developing & \multicolumn{2}{|c|}{51.6} & \multicolumn{2}{|c|}{48.4} & \multicolumn{2}{|c|}{43.1} & \multicolumn{2}{|c|}{45.5} & 11.4 \\
\hline Developed & \multicolumn{2}{|c|}{60.0} & \multicolumn{2}{|c|}{40.0} & \multicolumn{2}{|c|}{51.8} & \multicolumn{2}{|c|}{38.0} & 10.2 \\
\hline Aguiar and Gopinath & \multicolumn{2}{|c|}{57.3} & \multicolumn{2}{|c|}{42.7} & \multicolumn{2}{|c|}{50.3} & \multicolumn{2}{|c|}{40.1} & 9.5 \\
\hline Developing & \multicolumn{2}{|c|}{49.9} & \multicolumn{2}{|c|}{50.1} & \multicolumn{2}{|c|}{39.5} & \multicolumn{2}{|c|}{45.6} & 14.9 \\
\hline Developed & \multicolumn{2}{|c|}{60.0} & \multicolumn{2}{|c|}{40.0} & \multicolumn{2}{|c|}{51.8} & \multicolumn{2}{|c|}{38.0} & 10.2 \\
\hline Source of shock & Home & G8 & Home & G8 & Home & G8 & Home & G8 & Interest \\
\hline Type of shock & $\mathrm{P}$ & $\mathrm{P}$ & $\mathrm{T}$ & $\mathrm{T}$ & $\mathrm{P}$ & $\mathrm{P}$ & $\mathrm{T}$ & $\mathrm{T}$ & rate \\
\hline All Countries & 31.7 & 22.4 & 34.1 & 11.8 & 18.0 & 27.6 & 10.2 & 33.1 & 11.0 \\
\hline Developing & 39.0 & 12.5 & 36.1 & 12.3 & 9.2 & 33.9 & 10.6 & 35.0 & 11.4 \\
\hline Developed & 14.4 & 45.5 & 29.3 & 10.7 & 38.6 & 13.2 & 9.2 & 28.8 & 10.2 \\
\hline
\end{tabular}


Figure 1. International business cycles

Panel A. Developing Countries

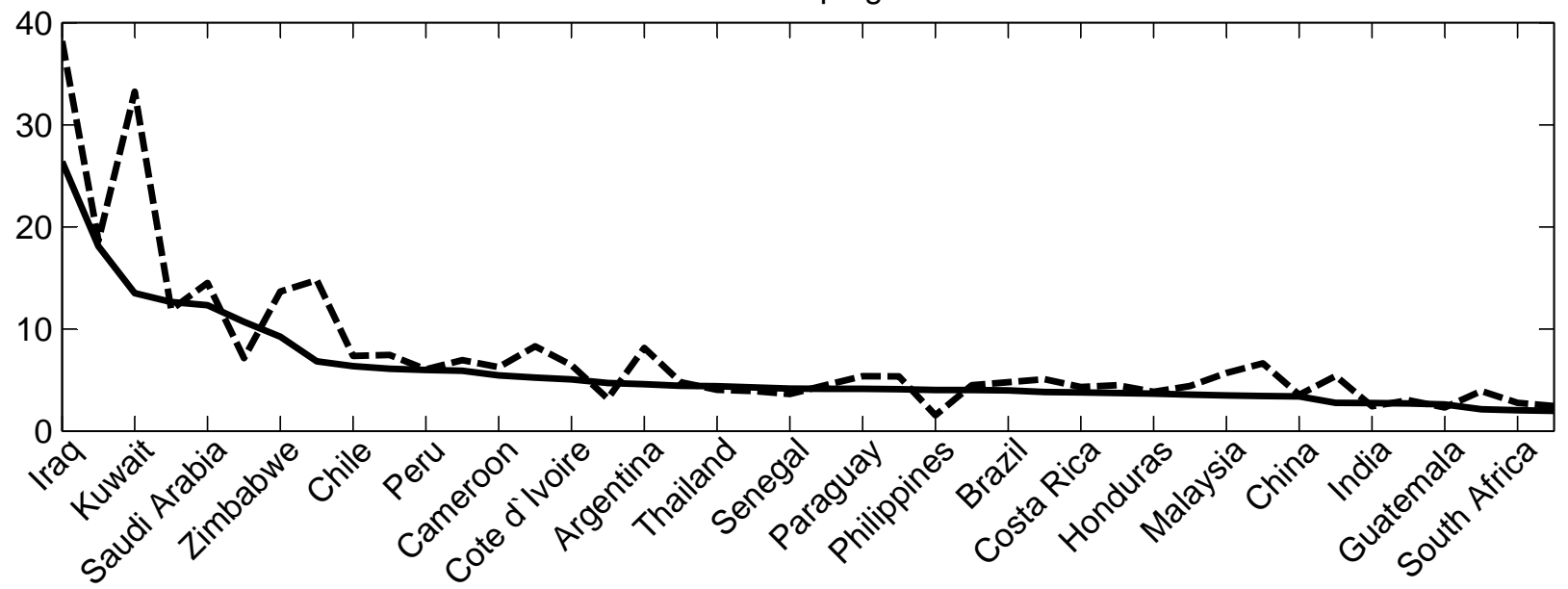

Panel B. Developed Countries

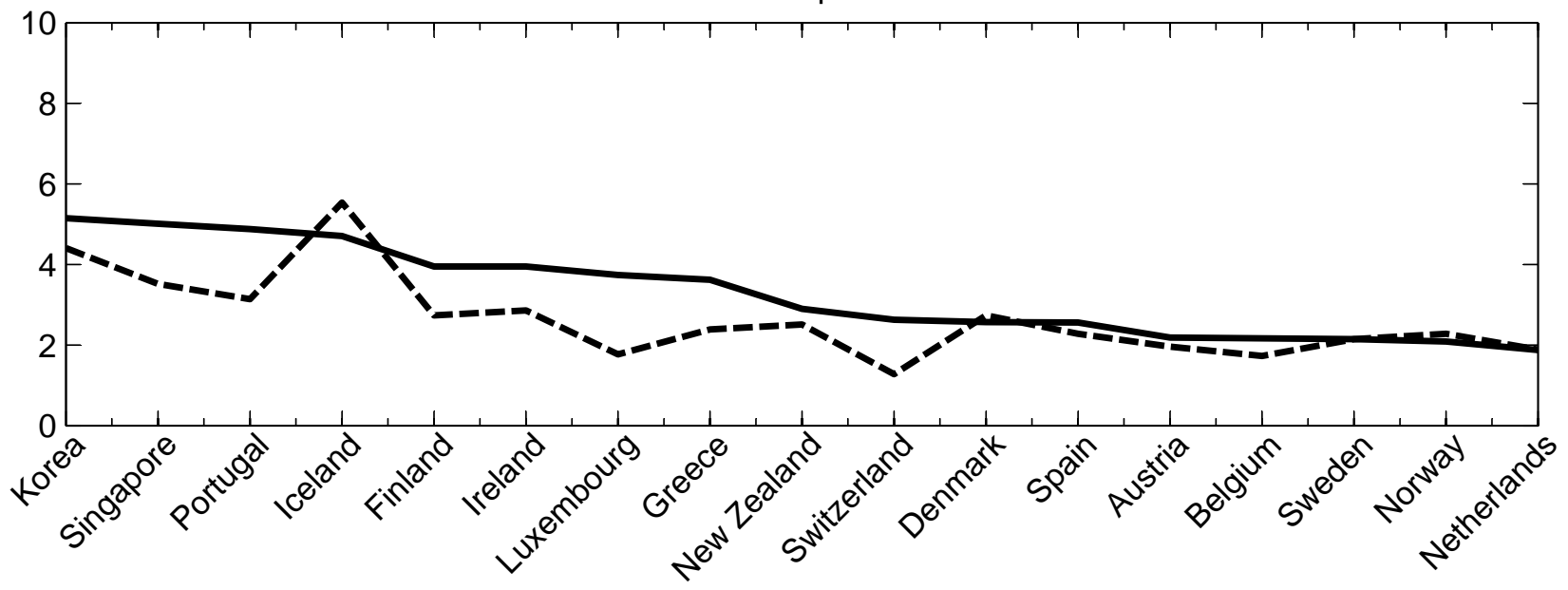

Panel C. G7 and Australia

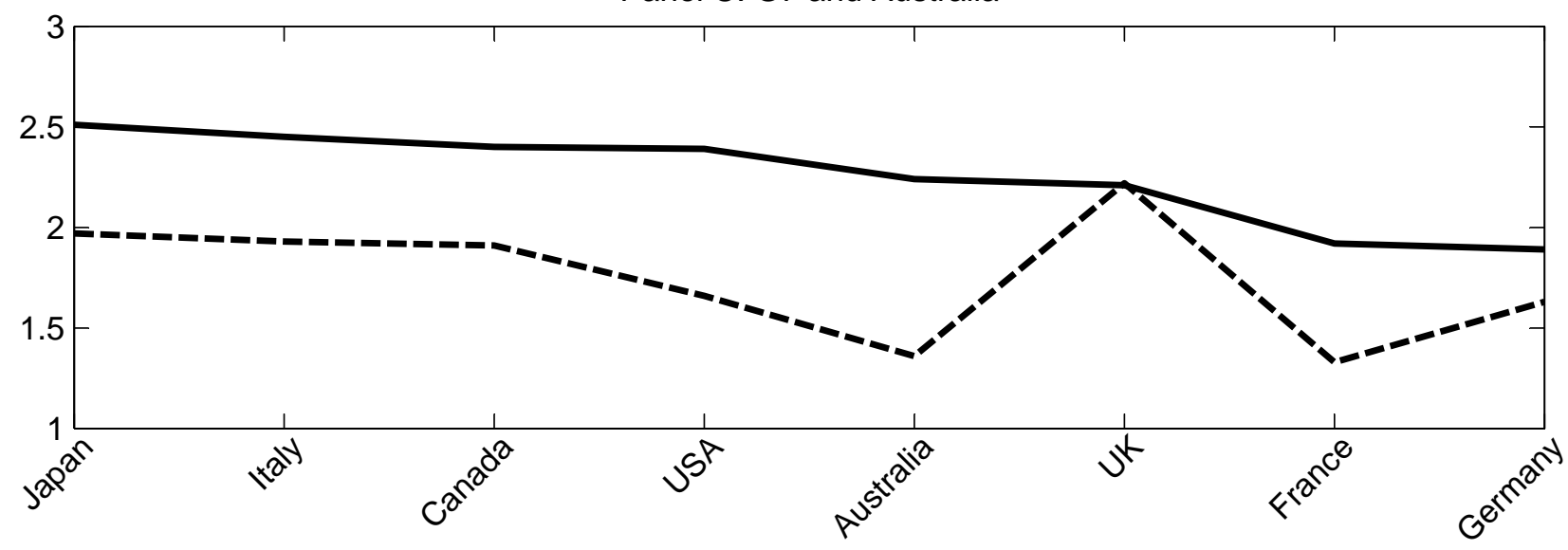


Figure 2. Proportion of output growth variance accounted for by permanent shocks: Comparison of DGSE model and SOE with productivity spillovers

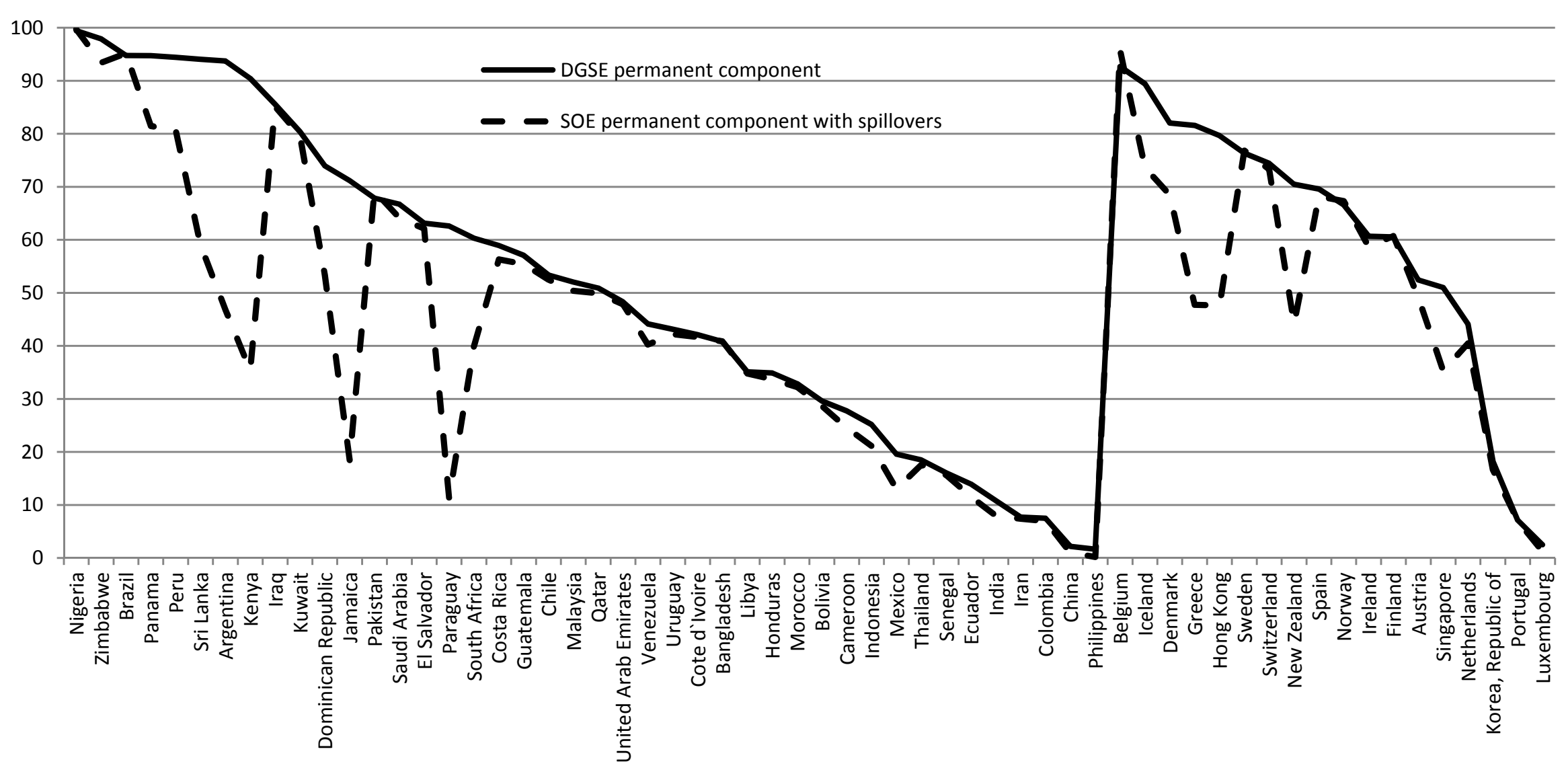


Figure 3. Proportion of output growth variance accounted forby permanent shocks:

Comparison of SOE model with productivity spillovers to SOE model without spillovers

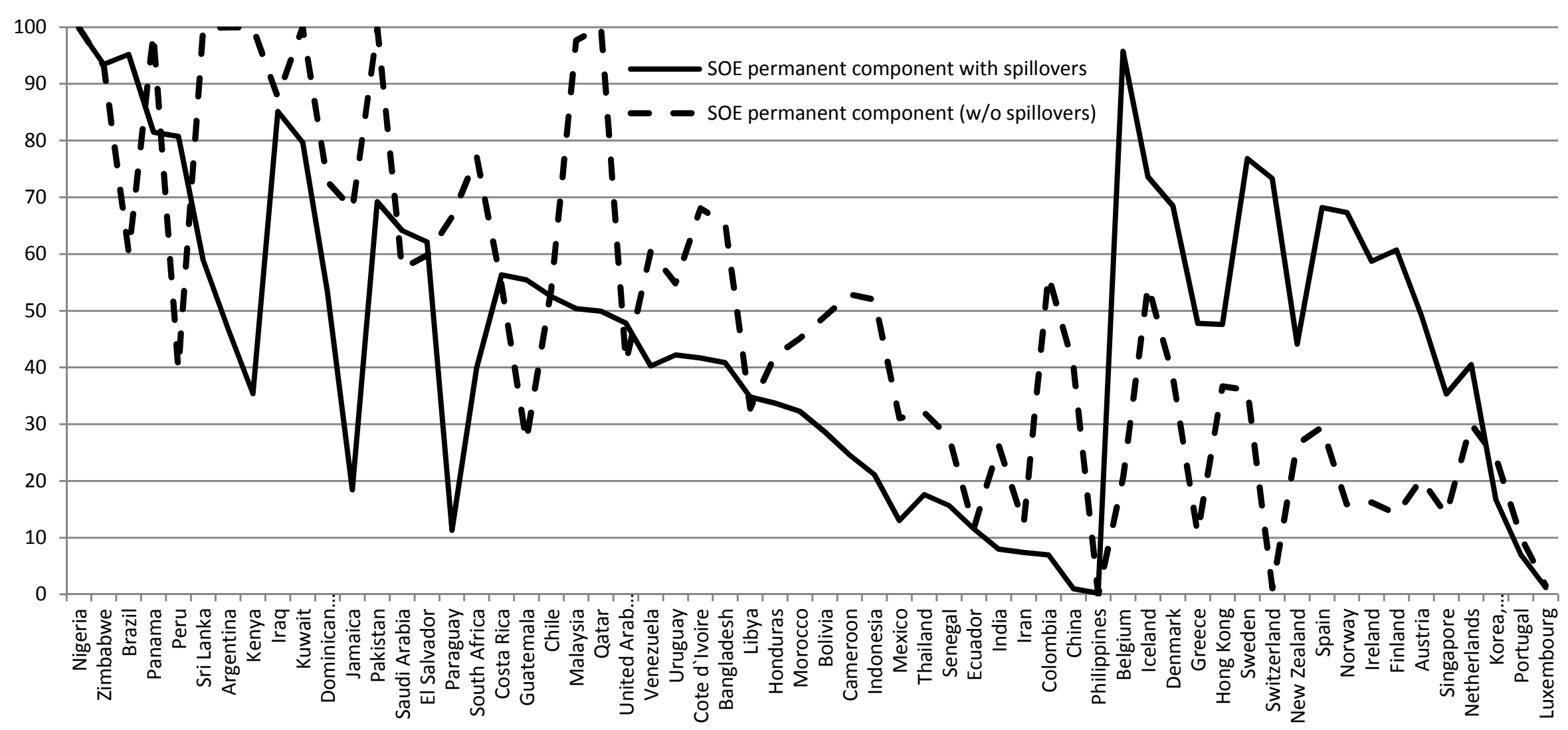

